\title{
Reserve Estimation Technique for Low Permeability Shale Gas Formations of Lower Indus Basin, Using Simulation Approach
}

\author{
Zafarullah Abroํ, Ali Nawaz Mengal' ${ }^{1}$, Abdul Haque Tunio², Adnan Aftab Nizamani ${ }^{3}$ \\ 1Department of Petroleum and Gas Engineering, Faculty of Engineering and Architecture, Balochistan University of \\ Information Technology, Engineering and Management Sciences, Quetta Pakistan, ${ }^{2}$ Institute of Petroleum Engineering \\ Mehran University of Engineering and Technology, Jamshoro, Pakistan, ${ }^{3}$ Department of Petroleum and Gas \\ Engineering, SZAB Mehran University of Engineering and Technology, Jamshoro, Pakistan
}

\begin{abstract}
Produced Natural Gas from the low permeability tight shale reservoirs are called as Shale Gas, has a great importance in economic terms of supply and demand because of natural gas prices. Shale is composed of a rock having sedimentary of clastic nature that contains mudstone and siltstone under the specific reservoir conditions of pressure and temperature are called Shale gas. Shales are of the soft nature formation that formed due to pre-existing rocks which have been elated, worn out and transported into a new form of rock. Shale is found in reservoir rock where organic material migrated upward and in areas where conventional clays are normally present. Shale is known as unconventional energy source. Due to high demand in population rate and increasing consumption of natural gas in transportation sector it is challenging for Pakistan to meet the energy requirements and needs in utilizing both conventional and unconventional energy resources. In this research study, the set of data, tools and methodology applied to estimate initial gas in place (IGIP), recoverable reserves, recovery factor, and risk analysis of shale gas reservoirs. The study reveals potential and characteristics of shale reservoir to grade the areas in term of shale thickness, its hydrocarbon generation potential, current depth and maturity for shale gas exploitation. Development of shale gas will be capable to overcome the gas needs for almost next 50 years.
\end{abstract}

Keywords: Tight Shale Gas Recovery; Reserve Estimation Technique; Reservoir Simulation

Corresponding author's email: abrozafar@gmail.com

\section{INTRODUCTION}

Shale gas is producible from its geological origin, typically an organic-rich, black shale. These are the types of source rocks of oil and gas. Shale gas states to in situ hydrocarbon gas existing in organic rich, fine grained, sedimentary rocks. Shale that produces the gas also meaning as a type of low matrix-permeability and low porosity reservoir rocks (Suarez-Ruiz and Hackley, 2012). Gas is deposited in shale source rocks in two major ways, adsorption and absorption within the organic matrix. Important parameters for shale gas deposits comprises, total organic carbon (TOC), thermal maturity, shale thickness, shale characteristics (porosity/permeability), and free gas fraction within pores and fractures, and adsorbed gas portion within the organic matrix. Shale gas is categorized as unconventional reservoir, and there are three forms of unconventional plays; Coal Bed Methane, Tight Gas and Shale Gas (Sunjay and Kothari, 2011). The estimations of unconventional hydrocarbons in world are about:

1. Coal bed methane 9,500 trillion cubic feet (Tcf) of gas in place.

2. Shale gas 15,000 trillion cubic feet (Tcf) of gas in place (Edwards et al., 2015).

3. Tight gas sands 7,400 trillion cubic feet (Tcf) of gas in place (Gomez and Wenwu, 2012).

\section{Shale Gas Composition}

Shale is a sedimentary rock fine-grained clastic composed of silt mud and silt sand that is mixture of tiny fragments, flakes of clay minerals and tiny fragments of quartz, calcite and other minerals. Shale is primarily composed of clastic rocks, usually shale with smaller quantities of sandstone and siltstone. Shale are composed of clays and silty clays compacted and deposited due to the over burden pressure. Shale with a high fraction of carbonate and quartz tend to be brittle and will "shatter". Shale contain clay tend to be yielding and to collapse instead of shattering Shale that produced the gas also function as low porosity and low matrix-permeability reservoir rocks (Suarez-Ruiz and Hackley, 2012). Shale is naturally composed of clay 
minerals and quartz grains and the typical color is gray. The shale composition depends upon the amount of total organic carbon (TOC) (Guarnone et al., 2012)

Table 1: Composition of Shale Gas Reservoirs

\begin{tabular}{|l|l|}
\hline Total Organic Carbon (wt \%) & $\mathbf{0 . 5 0}$ \\
\hline Tmax(C)-Ro & $455-1.0$ \\
\hline Transformation Ratio & 80 \\
\hline Gas Dryness (\%) & 80 \\
\hline Total Porosity (\%) & 4 \\
\hline Gas Filled Porosity (\%) & 2 \\
\hline Net Thickness (m) & 15 \\
\hline Shale (\%) & 60 \\
\hline Silica (\%) & 25 \\
\hline Carbonate (\%) & $<25$ \\
\hline
\end{tabular}

\section{Estimation of Shale Gas in Pakistan}

There is 30-35 trillion cubic feet (TCF) potential of shale gas in Pakistan. Possible producible reserves are about 3.5 TCF from present discoveries. Shale gas reserves are about 3.9 TCF in Miano field, Sindh and recovery from these reserves is about 1.5 TCF. (U.S. Energy Information, 2012).

\section{MATERIALS AND METHODS}

In this research study, three separate simulators ECLIPSE 100, ECLIPSE 300 and ECLIPSE 500 are used to simulate the data and results. ECLIPSE 100 used for black oil modal and ECLIPSE 300 used in compositional models. ECLIPSE 100 used for single and multiphase system.

\section{RESULTS AND DISCUSSION}

The results by simulating reservoirs which is mainly composed of gas components with following composition:

Table 2: Composition of the components present in the gas

\begin{tabular}{|c|c|}
\hline Components & Composition \\
\hline $\mathrm{Co}_{2}$ & 0.019 \\
\hline $\mathrm{C} 1$ & 0.551 \\
\hline $\mathrm{C} 2$ & 0.130 \\
\hline $\mathrm{C} 3$ & 0.100 \\
\hline $\mathrm{IC}-4$ & 0.050 \\
\hline $\mathrm{N}-\mathrm{C} 4$ & 0.050 \\
\hline $\mathrm{I}-\mathrm{C} 5$ & 0.045 \\
\hline $\mathrm{N}-\mathrm{C} 5$ & 0.045 \\
\hline $\mathrm{C} 6$ & 0.005 \\
\hline $\mathrm{C} 7+$ & 0.005 \\
\hline
\end{tabular}


Reserve Estimation Technique for Low Permeability Shale Gas Formations of Lower Indus Basin, Using Simulation Approach

\section{Model: Shale Tight Gas Reservoir}

Table 3: Properties/ parameters used for model 1

\begin{tabular}{|l|l|l|l|l|c|l|}
\hline $\begin{array}{l}\text { Pressure } \\
\text { (Pisa) }\end{array}$ & $\begin{array}{l}\text { Temperature } \\
(\mathbf{F})\end{array}$ & $\begin{array}{l}\text { Porosity } \\
(\%)\end{array}$ & $\begin{array}{l}\text { Kh } \\
(\mathbf{m D})\end{array}$ & $\begin{array}{l}\text { Kv } \\
(\mathbf{m D})\end{array}$ & Gas production rate (Mscf/day) & $\begin{array}{l}\text { Depth } \\
(\mathbf{f t})\end{array}$ \\
\hline 5000 & 850 & 0.06 & 1 & 0.1 & 1500 & 10,000 \\
\hline
\end{tabular}

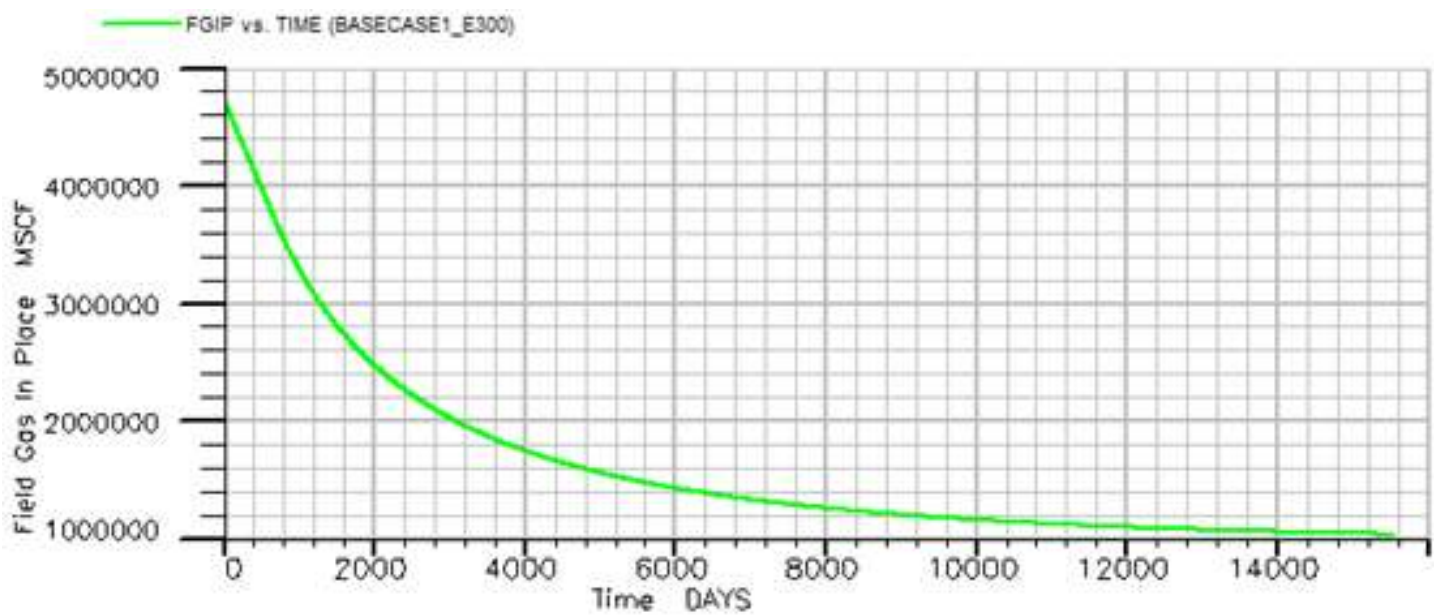

Figure 1: Field Gas in Place vs Time

The time is shown on $\mathrm{X}$-axis and field gas in place is shown on $\mathrm{Y}$-axis. The graph shows the field initial gas in place is 4700000 MMSCF declining to zero with respect to time in a time interval of 42.8 years.

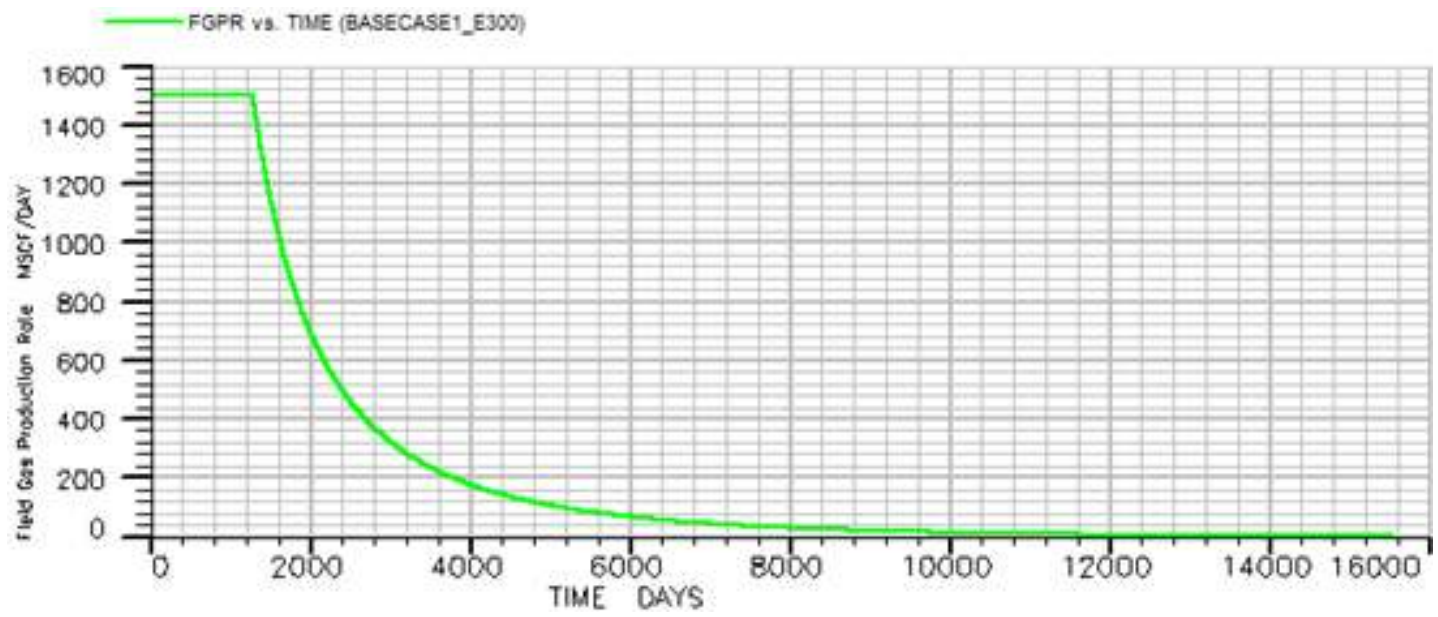

Figure 2: Field Gas Production Rate vs Time

The above graph 2 expresses relation between field gas production rate vs time. The time on $X$-axis and field gas production rate on Y-axis. The graph shows that gas is producing per day. The graph shows that field initial gas production is $1550 \mathrm{MSCF} /$ day remain same up to 3.4 years after which gas production rate start decline with respect to time (Ghorayeb and Holmes, 2007). 
Reserve Estimation Technique for Low Permeability Shale Gas Formations of Lower Indus Basin, Using Simulation Approach

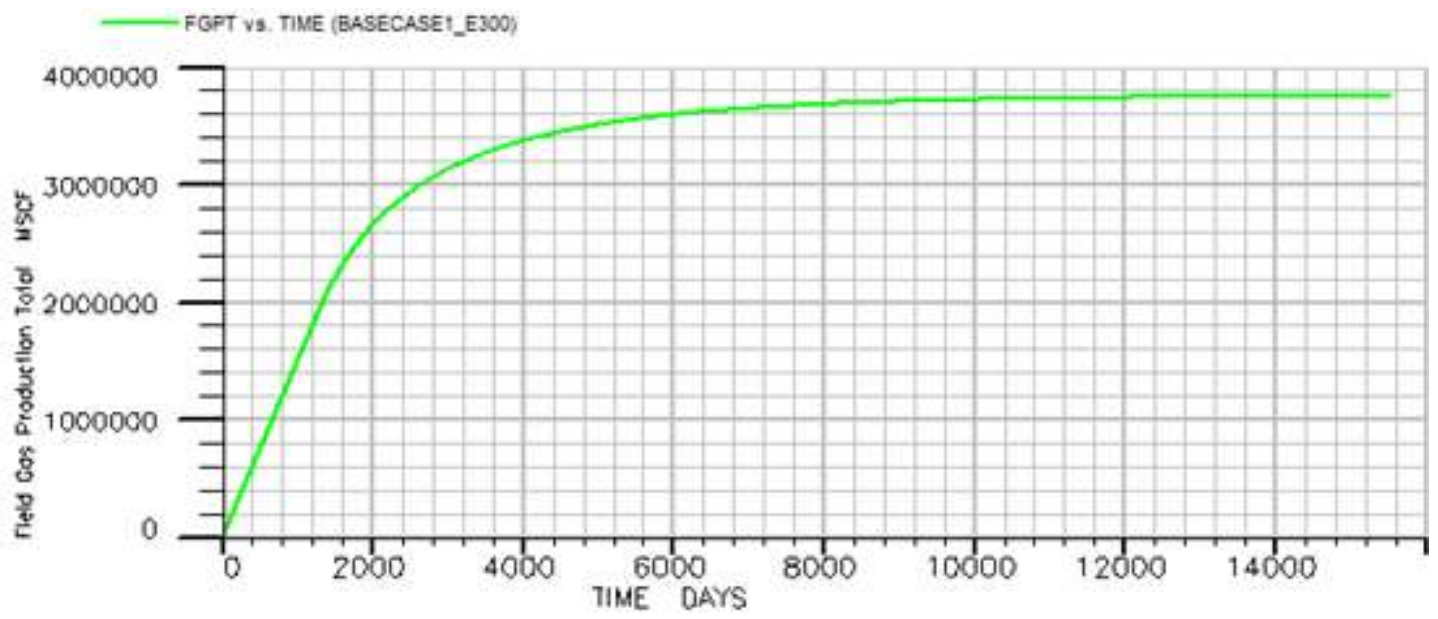

Figure 3: Field Gas Production total vs Time

The graph 3 of field gas production total vs time. The $X$-axis reflects total production we get from the gas well and the Y-axis shows field gas total production. The total of 3800000 MSCF of gas is produced out of $4700000 \mathrm{MSCF}$ of gas in 42.7 years.

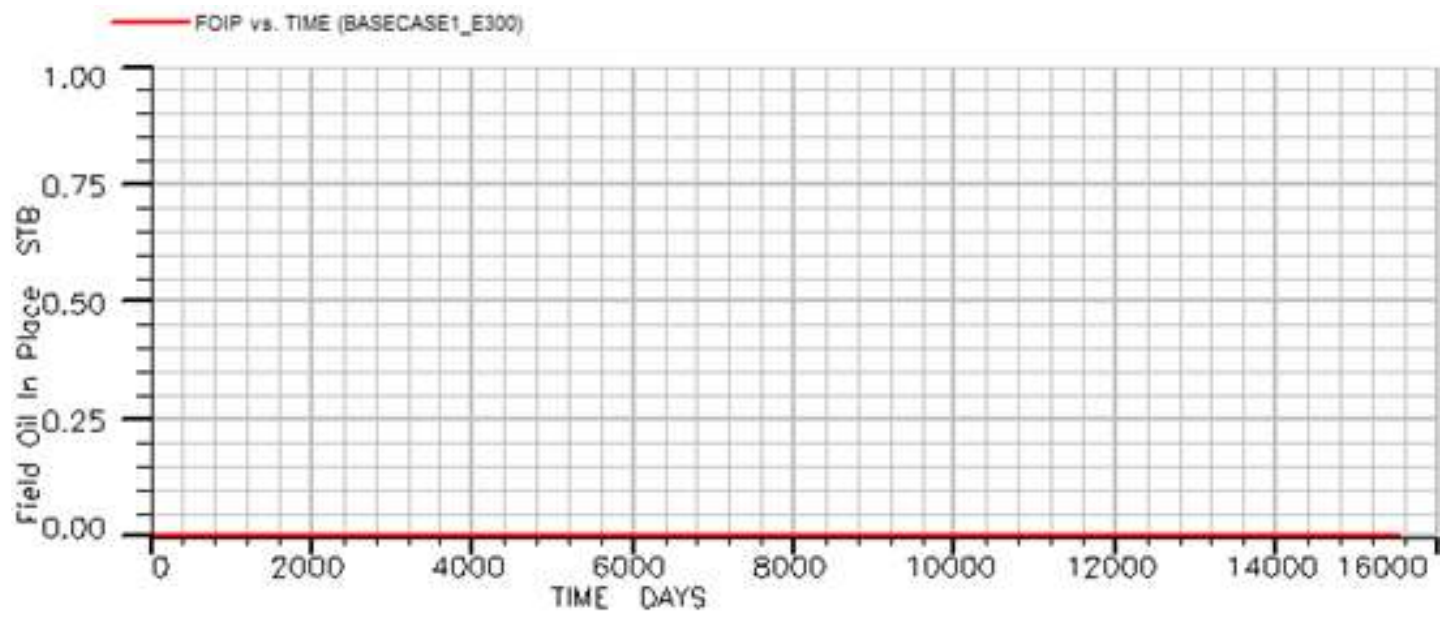

Figure 4: Field oil in place vs time

The graph 4 shows field oil in place vs time. The time is on X-axis and field oil in place is on $\mathrm{Y}$-axis. The graph shows that a constant zero production of oil from initial to end, the reservoir contains zero oil.

The graph 5 shows relationship between field oil production rate $V s$ time. The time is on $X$-axis and field oil production rate is on $\mathrm{Y}$-axis. The graph represents amount of oil production per day. The straight line reflects behavior of zero production of oil per day (Ariwa and El-Qawasmeh, 2011). 
Reserve Estimation Technique for Low Permeability Shale Gas Formations of Lower Indus Basin, Using Simulation Approach

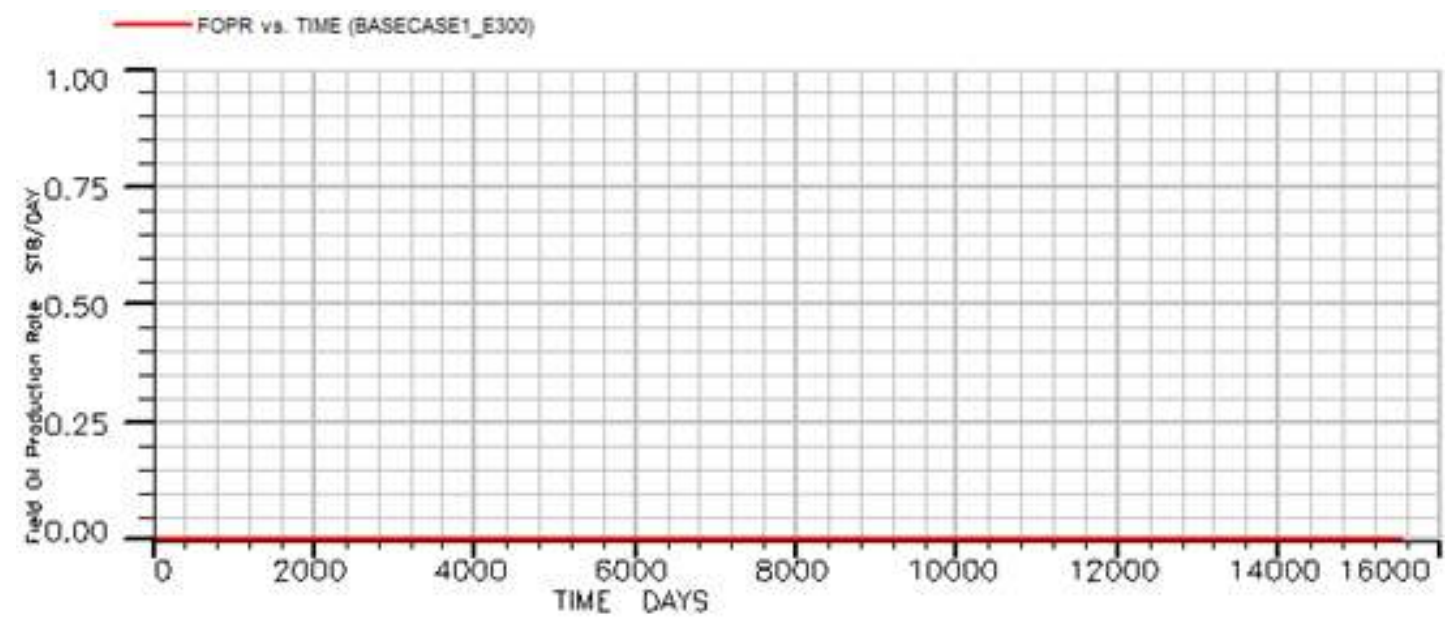

Figure 5: Field oil production rate vs time

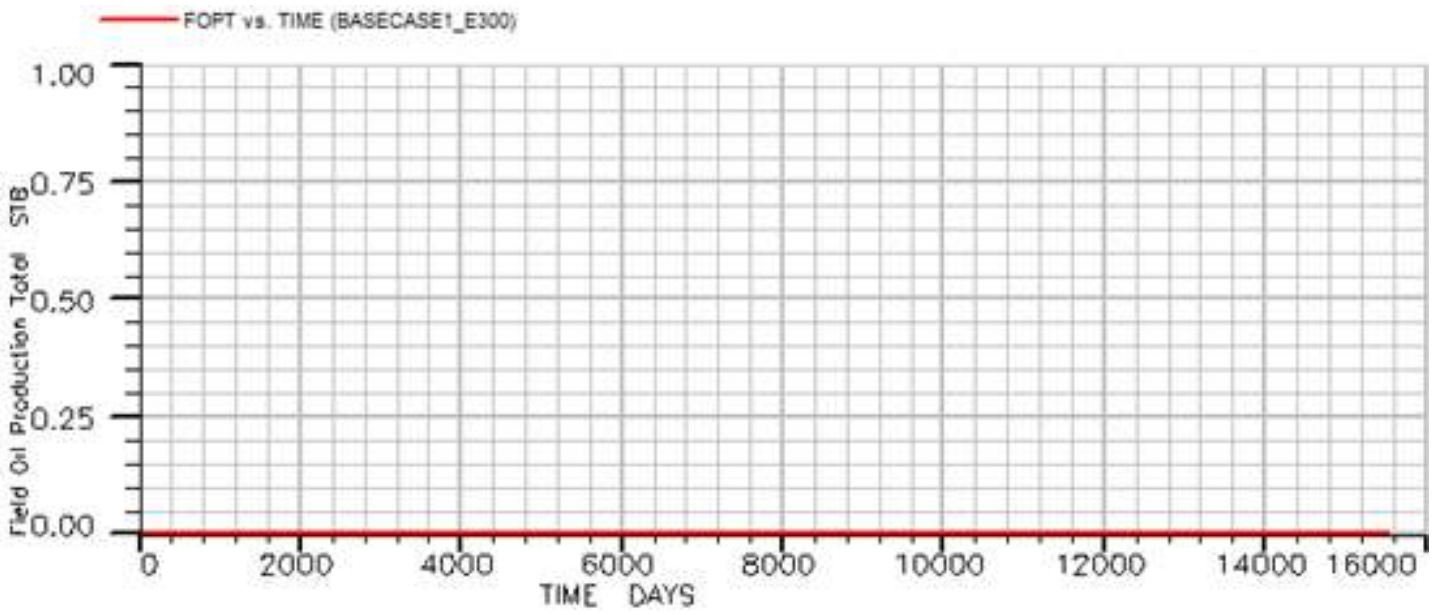

Figure 6: Field Oil production total vs time

The graph 6 shows relationship between field oil production total Vs time. The time is on $X$-axis and field oil production on $\mathrm{Y}$-axis. The graph shows that total oil is produced in a particular time interval. The straight line of zero oil production reflects no oil is present in the reservoir.

The graph 7 shows field pressure vs time. The time is on $\mathrm{x}$-axis and field pressure is on $\mathrm{Y}$-axis. The graph shows the effect of gas production on pressure with respect to time. Initial pressure is 5150 Psia which is decreasing constantly with respect to time to 1000 psia. 
Reserve Estimation Technique for Low Permeability Shale Gas Formations of Lower Indus Basin, Using Simulation Approach

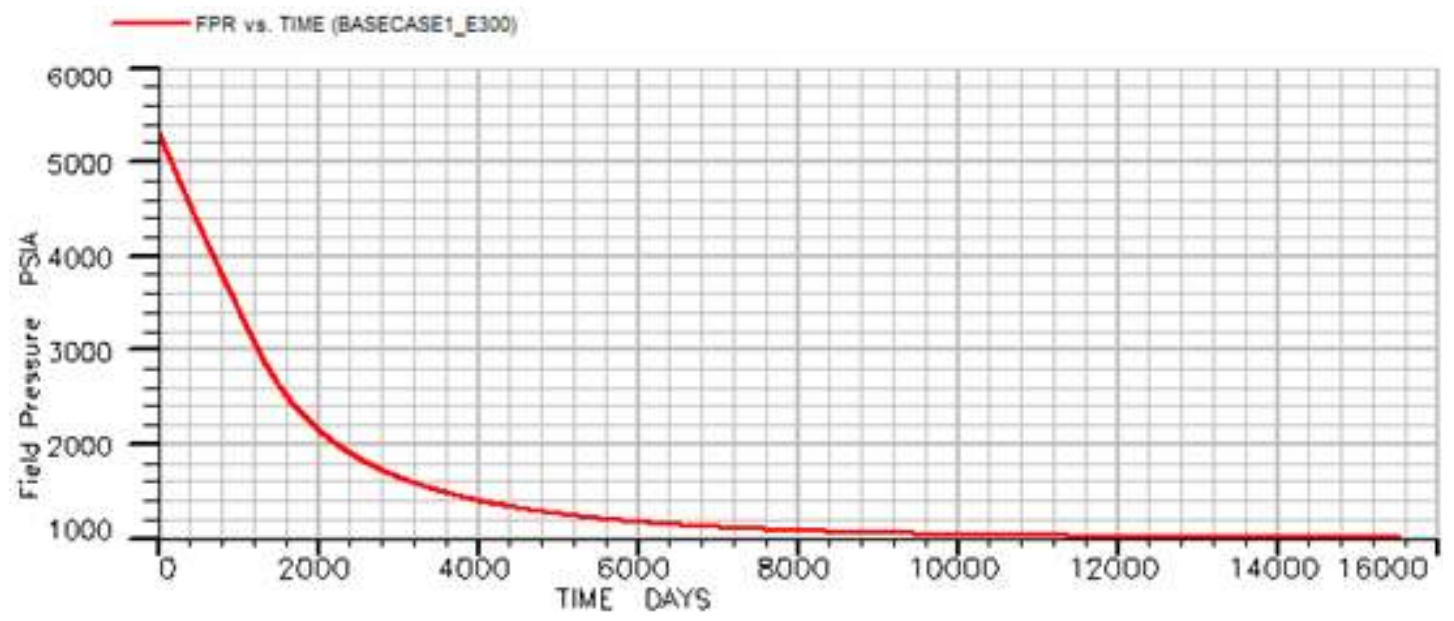

Figure 7: Field pressure vs time

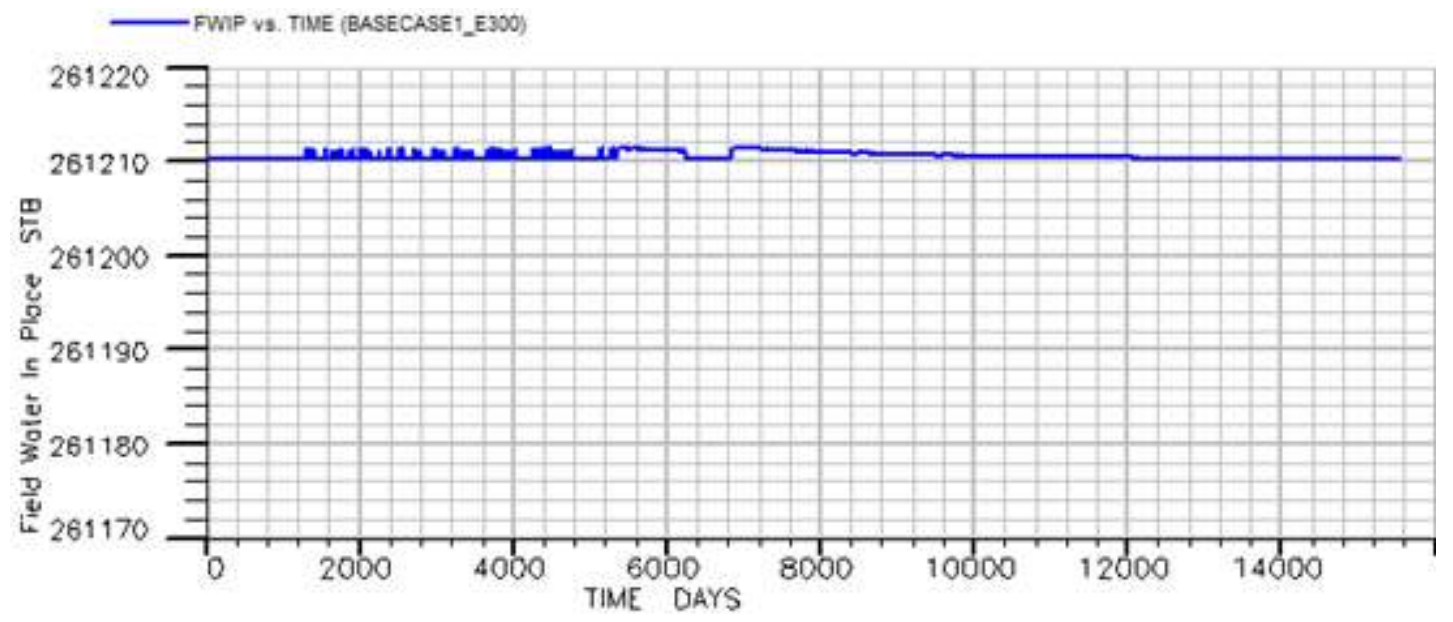

Figure 8: Field water in place vs time

The graph 8 shows relationship between field water in place vs time. The time is on X-axis and field water is on y-axis. The graph shows amount of water in the reservoir. The straight line shows that a total of 261210 STB of water is present.

The graph 9 shows relationship between field water production rate vs time. The time is on $X$-axis and field water production on Y-axis. The graph shows amount of water production per day. The straight line of zero production of water from the reservoir. 
Reserve Estimation Technique for Low Permeability Shale Gas Formations of Lower Indus Basin, Using Simulation Approach

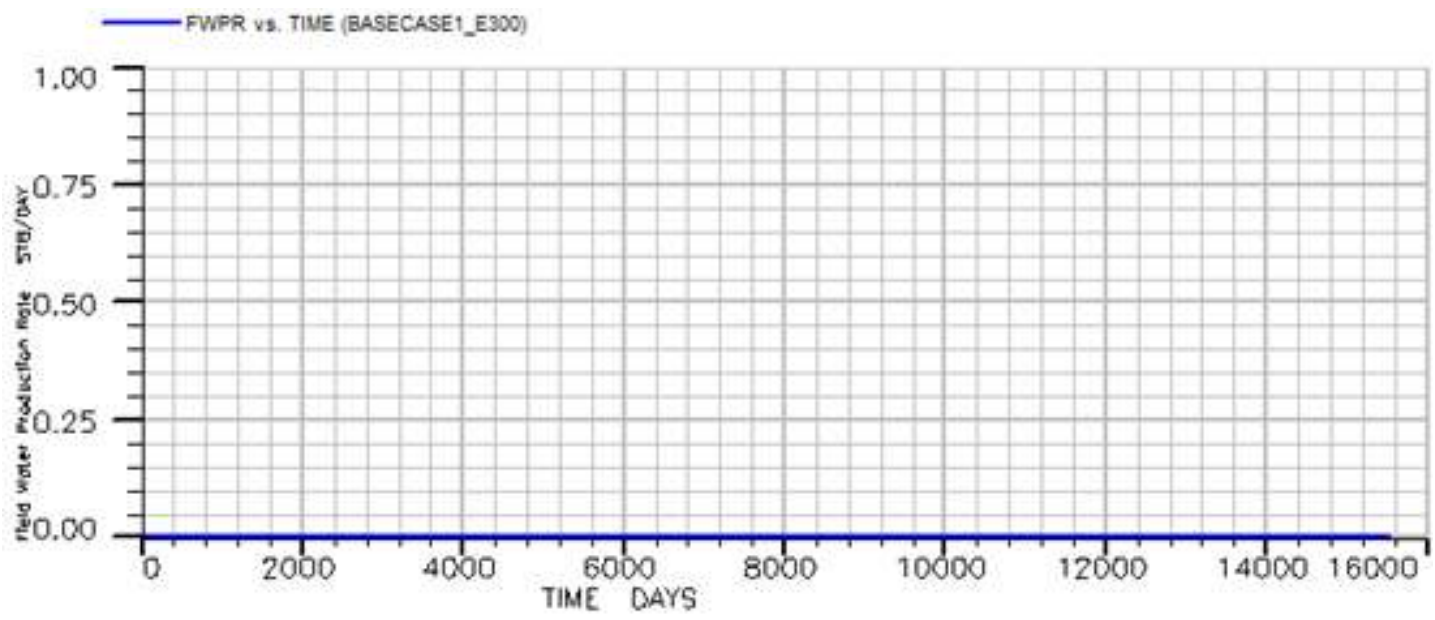

Figure 9: Field water production rate vs time

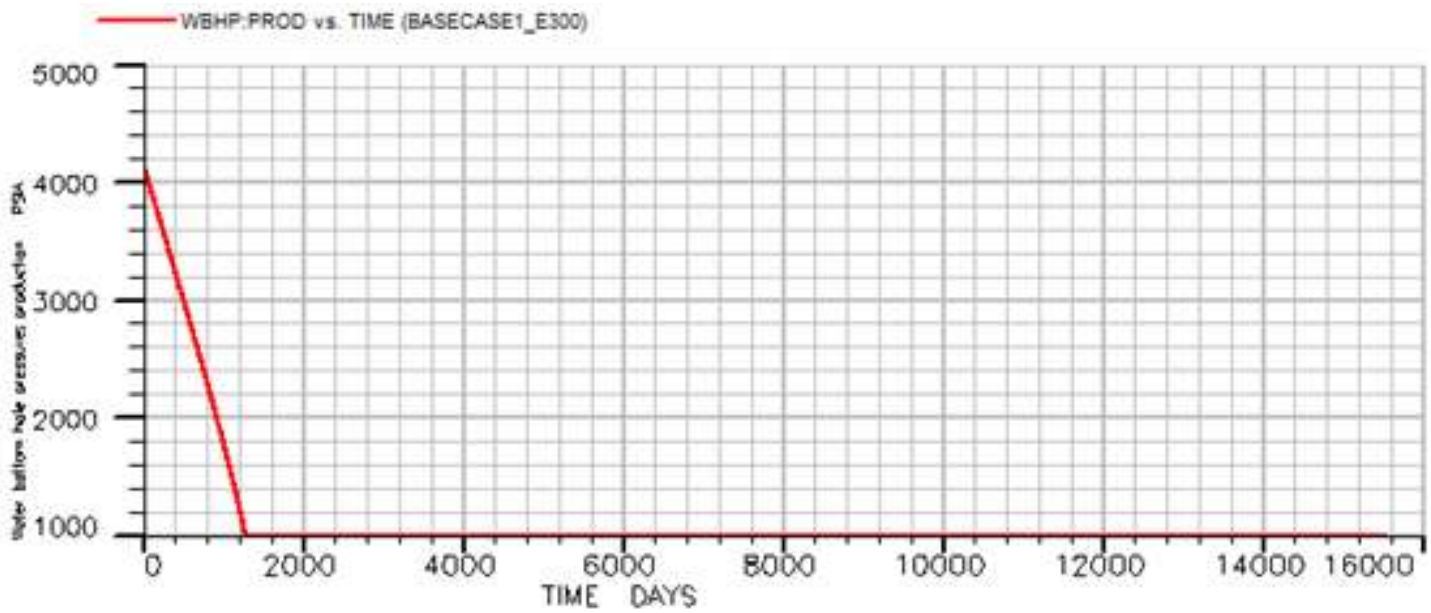

Figure 10: Field water production Vs time

The graph 10 shows relationship between field water production total vs time. The time is on $\mathrm{X}$-axis and field water production total is on Y-axis. The graph show total water is produced from the reservoir. The constant straight line shows zero production of water.

The graph 11 shows relationship between water bottom hole pressure: production vs. time. The time is on $\mathrm{X}$-axis and water bottom hole pressure production is on the $\mathrm{Y}$-axis. This graph the effect of production on bottom hole pressure with respect to time. The well bottom hole pressure: production decline sharply during the time interval of 0 to 4.8 years from 5000 psia to 1000 psia which remains same for 22.7 years. 


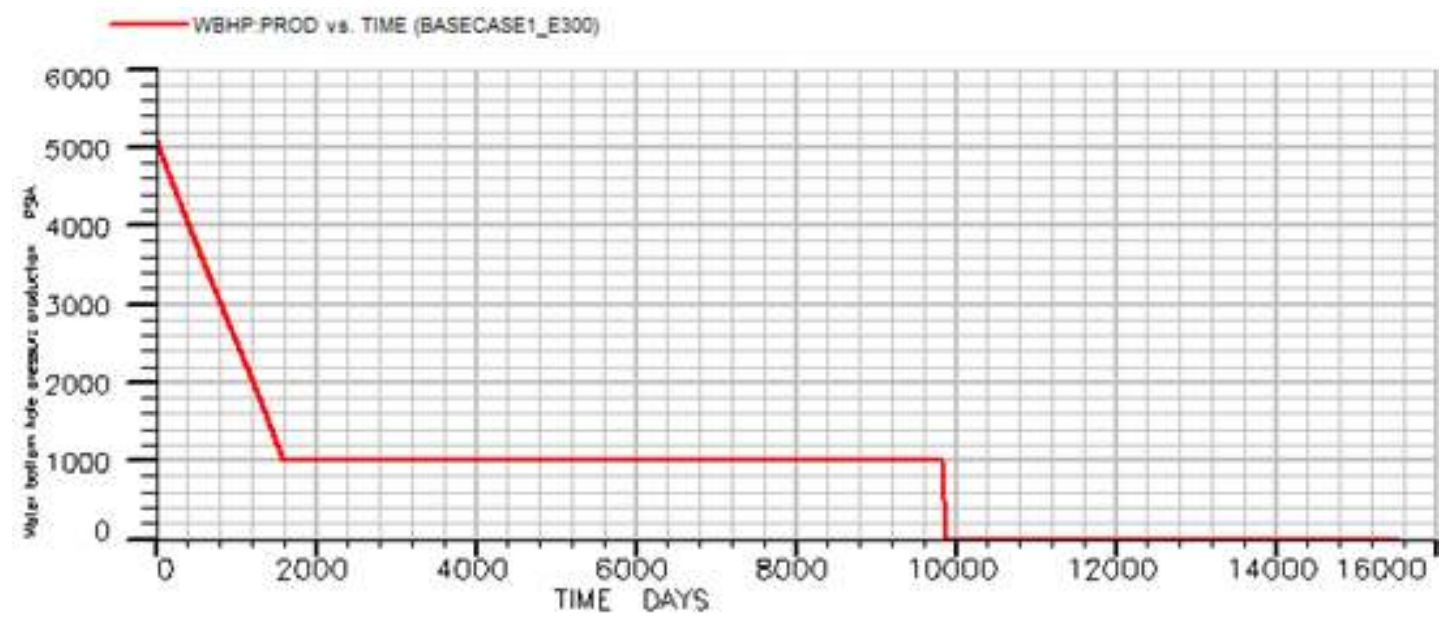

Figure 11: Water bottom hole pressure vs time

\section{CONCLUSION}

- Tight Shale gas reservoir with low permeability $0.1 \mathrm{md}$ (milli darcy) and porosity $0.06 \%$ can produce at optimum rate when produced at constant increasing rate.

- For optimized recovery of shale gas reservoirs, the hydraulic fracturing operations are economical.

- Efficient recovery of tight shale gas reservoirs will be helpful in maintaining the energy crisis in future situation.

\section{REFERENCES}

- Sunjay and Kothari N. (2011). An Unconventional Energy Resources: Shale Gas. Paper presented at Offshore Mediterranean Conference and Exhibition Ravenna, Italy, Pp 2-3.

- Gomez S, He W. (2012). Fighting Wellbore Instability: Customizing Drilling Fluids Based on Laboratory Studies of Shale-Fluid Interactions, SPE-155536, presented at IADC/SPE Asia Pacific Drilling Technology Conference in Tianjin, China, Pp 1-4.

- Suárez-Ruiza I, Hackleyd PC. (2012). Review and update of the applications of organic petrology: Part 1, geological applications. International Journal of Coal Geology 99:54-112.

- Edwards RWJ, Celia MA, Bandilla KW, Doster F, Kanno CM. (2015). A Model to Estimate Carbon Dioxide Injectivity and Storage Capacity for Geological Sequestration in Shale Gas Wells. Environ. Sci. Technol. 49(15):9222-9229.

- Guarnone M, Rossi F, Negri E, Grassi C, Genazzi D, Zennaro R. (2012). An unconventional mindset for shale gas surface facilities. Journal of Natural Gas Science and Engineering 6:14-23.

- Sondergeld CH, Newsham KE, Comisky JT, Rice MC, Rai CS. (2010). Petrophysical considerations in evaluating and producing shale gas resources. In SPE Unconventional Gas Conference. Society of Petroleum Engineers. pp. 1-34.

- Ghorayeb K and Holmes JA. (2007). Black Oil Delumping Techniques Based on Compositional Information from Depletion Processes. SPE Reservoir Evaluation \& Engineering 10(5):1-11.

- El-Qawasmeh EAE. (2011). Digital Enterprise and Information Systems. International Conference, DEIS 2011, London, UK, 2011. 